\title{
Las funcionalidades de los grafismos en los mensajes periodísticos: análisis y propuesta sistematizadora
}

\author{
Manuel MonTES VozMEDiAnO \\ manueljavier.montes@urjc.es \\ Universidad Rey Juan Carlos de Madrid
}

Recibido: 26 de marzo de 2014

Aceptado: 5 de septiembre de 2014

\section{Resumen}

Los diversos estudios sobre la representación de los mensajes periodísticos no se han decantado por abordar un componente básico en la confección de estos mensajes como son los recursos tipográficos no textuales o grafismos. Los resultados de la investigación constatan la relevancia y versatilidad de este componente del sistema gráfico. Su análisis pormenorizado en un sector como el de las revistas femeninas de alta gama, caracterizado por estar a la vanguardia de la representación formal de los mensajes periodísticos, nos permite realizar una propuesta sistematizadora de las funcionalidades de los grafismos que sea de utilidad tanto para investigadores como para profesionales.

Palabras clave: Mensaje periodístico, análisis, recursos tipográficos, grafismos, funcionalidades, revistas femeninas, diseño gráfico.

\section{The Functions of Graphisms in the Journalistic Messages: Analysis and Proposal Systematizing}

\begin{abstract}
Differents researchs on the visual representation of the journalistic messages have not opted to address a key component in the production of these messages such as graphisms or textual no typographic resources. The results of the research note the relevance and versatility of this component of graphics system. The detailed analysis in the sector of high end women's magazines, characterized by being in the vanguard of the formal representation of journalistic messages, allows us to make a proposal to its functionality systematizing it referential for both researchers and professionals.

Keywords: Journalistic message, analysis, typographic resources, graphisms, functionality, women's magazines, graphic design.

\section{Referencia normalizada}

MONTES VOZMEDIANO, Manuel (2015): "Las funcionalidades de los grafismos en los mensajes periodísticos: análisis y propuesta sistematizadora”. Estudios sobre el Mensaje Periodístico. Vol. 21, Núm. 1 (enero-junio), págs.: 421-435. Madrid, Servicio de Publicaciones de la Universidad Complutense.
\end{abstract}

Sumario: 1. Introducción; 1.1. Objetivos; 1.2. Ámbito de estudio. 2. Fuentes y metodología; 2.1. Fuentes; 2.2. Metodología; 2.3. Hipótesis. 3. Desarrollo de la investigación. 4. Resultados; 4.1. Propuesta de funcionalidades de los grafismos. 5. Conclusiones. 6. Referencias bibliográficas.

\section{Introducción}

Nuestro interés reside en el estudio de aquellos mensajes periodísticos que precisan una representación formal, como sería el caso de los mensajes de la denominada prensa escrita, con independencia del tipo de medio (ya sean diarios, revistas o suplementos) y de su soporte (papel, pantalla o similar).

Es posible acometer el análisis formal de un mensaje periodístico de muy diversas maneras. Una estrategia válida sería estudiar particularmente cada uno de los componentes básicos de este tipo de representaciones visuales. Algunos de estos compo- 
nentes como las imágenes, los textos o el color han sido objeto de numerosos estudios. Otros elementos, como es el caso de los recursos tipográficos, no han sido, sin embargo, objeto preferencial de análisis ${ }^{1}$. Si bien pueden pasar desapercibidos en el diseño, la aportación de los recursos tipográficos resulta determinante, especialmente si se trata de mensajes cuyo contenido es complejo, pues facilitan la estructuración y jerarquización del mismo.

\subsection{Objetivos}

Si visualizamos las páginas, impresas o en soporte digital, de cualquier diario, revista o publicación similar comprobaremos que es un hecho habitual la inclusión de los recursos tipográficos -así los denominan autores como Canga (1994), Martín Aguado y Armentia Vizuete (1995) o Zorrilla (1999)-, si bien son también conocidos como recursos gráficos o grafismos por autores como García Yruela (2003) o Costa (1992). Si resulta que su uso es tan frecuente como se puede colegir de la mera observación nos parece oportuno analizar cuál es el papel y qué funciones desempeñan en la confección del mensaje periodístico.

A las aportaciones de los autores ya mencionados deben sumarse otras igualmente relevantes como las de Gordon y Dodd (1994), González Díez y Pérez Cuadrado (2001) o Martínez de Sousa (2005) que nos han permitido definir una tipología de los recursos tipográficos (filetes, subrayados, orlas, recuadros, topos o bolos, señalizadores, tramas y fondos y otros caracteres tipográficos) así como asociar a estos grafismos ciertas funciones compositivas (como estructurar o connotar).

La definición de un marco de estudio nos permitirá extraer resultados concretos en ese ámbito como su frecuencia de uso, las tipologías más empleadas o si se da un uso combinado de los recursos tipográficos. Por otra parte, registraremos las funcionalidades compositivas tomando como partida los usos que mencionan los autores de referencia, pero sin descartar la inclusión de nuevas funcionalidades. También constataremos si existe una correlación entre los grafismos y las funciones que se les asocian, lo que nos permitirá definir cuáles son los más versátiles. Finalmente, consideramos que el registro obtenido posibilitará ofrecer una propuesta sistematizadora de las funcionalidades de los grafismos.

Por último, los que desarrollamos la labor docente impartiendo materias que tienen como actor principal el mensaje periodístico y dirigimos proyectos de Fin de Grado versados en esta misma materia, tenemos la doble satisfacción de aportar conocimientos teóricos en el presente a los que serán los profesionales del mañana lo que, esperamos, redunde en la mayor eficacia comunicativa de los mensajes periodísticos que confeccionen.

${ }^{1}$ En el estudio de las cabeceras de los diarios españoles realizado por González Díez y Pérez Cuadrado (2014) una de las variables registradas es la presencia de los recursos tipográficos no textuales, que se emplea en el $62,5 \%$ de las cabeceras analizadas. No obstante, al limitarse el estudio a las cabeceras no puede haber una amplia variedad como se constata que en 74 de los 75 casos el grafismo usado sea el filete. 


\section{2. Ámbito de estudio}

Nos hemos decantado por el análisis de los mensajes periodísticos de los medios impresos ya que aún tienen una gran relevancia en nuestro país. Unas cifras que, entendemos, nos pueden servir de orientación sobre su situación de preponderancia son las referidas a las inversiones publicitarias, ya que estos ingresos están determinados fundamentalmente por la audiencia de dichos medios. Según el Infoadex ${ }^{2}$ de 2013 -cuyos datos hacen referencia a 2012- los medios de comunicación impresos -considerando como tales a diarios, revistas y dominicales- ocupan el segundo puesto del ranking de inversión (por detrás de la televisión), con una cuota del 24,4\% (1.132 millones de euros), mientras que Internet logra el 19\% de la inversión (880,5 millones de euros).

Acotando aún más los medios impresos nos decantamos por las revistas, un tipo de publicaciones que se ha caracterizado por ser un ámbito de vanguardia, al menos en lo que se refiere a la comunicación gráfica, y un entorno que ha propiciado los experimentos visuales. Autores como Owen consideran que las aportaciones de la revista han sido notables en "el desarrollo de los principios del diseño moderno y de la expresión visual, la evolución técnica y artística" (Owen, 1991, 6). Entendemos pues que la elección de este ámbito nos permitirá extraer interesantes conclusiones. Puesto que era preciso decantarse por algunas publicaciones específicas para realizar el trabajo de campo, se ha optado por las denominadas "revistas femeninas de alta gama" que Cabello (1999: 156), en su estudio del mercado de las revistas en España, define como un tipo de publicaciones preocupadas por la calidad formal del producto: mejor papel, diseño y fotografía. En este selecto grupo Cabello sólo incluye cuatro cabeceras que, en sus ediciones españolas, han sido objeto de estudio: Elle, Marie Claire, Telva y Vogue. En su tipología de las revistas femeninas Menéndez Menéndez (2013) también sitúa en el mismo compartimento estas cabeceras.

\section{Fuentes y metodología}

Nuestro análisis se fundamenta en una metodología descriptiva de los mensajes periodísticos, focalizada en las características formales de grafismos. No obstante, también se ha registrado otras variables como las temáticas o géneros periodísticos de las unidades de análisis, para determinar si existen relaciones entre unas y otra variables (formales y de contenido). Se han analizado los ejemplares editados en España de las cuatro cabeceras ya mencionadas: Elle, Marie Claire, Telva y Vogue. Se ha tenido como referencia un periodo de tiempo de seis años, desde 2004 hasta 2009. Los ejemplares analizados en 2004 sirvieron para elaborar una primera ficha de análisis que luego fue depurada y aplicada al periodo 2005-2009.

2 La compañía Infoadex elabora, entre otros, un informe del mismo nombre que determina la inversión publicitaria realizada en los medios de comunicación en España. Las cifras citadas corresponden al volumen de negocio de los denominados medios convencionales: televisión, diarios, revistas, radio, exterior (publicidad situada en lugares como las vallas publicitarias o las marquesinas), dominicales, Internet y cine. 


\subsection{Fuentes}

Como trabajo de observación documental se ha tenido prácticamente como única fuente la sede de la Biblioteca Nacional situada en Madrid. De los ejemplares seleccionados para el estudio, unos pocos pudieron ser analizados por el autor sin recurrir a ninguna institución, al disponer de ellos, mientras que el resto fueron estudiados en la Biblioteca Nacional. Dicha entidad no contaba entre sus fondos con cinco de los ejemplares seleccionados inicialmente: tres correspondían a la revista Elle (noviembre de 2007, febrero y junio de 2008), uno a Telva (febrero de 2006) y otro a Vogue (octubre de 2007). Sólo en esta circunstancia se tuvo que recurrir a las editoriales que, en los tres casos, optaron por facilitar -tras las diferentes solicitudes presenciales, telefónicas y a través de correos electrónicos- los ejemplares en formato digital.

\subsection{Metodología}

Este trabajo de investigación es de carácter monográfico, ya que se centra a uno de los elementos empleados en la representación formal de los mensajes periodísticos: los grafismos. La metodología empleada es la descriptiva y, por tanto, de naturaleza empírica, que es respaldada y utilizada por autores como Joly (1999), Olmo (2004) o Heredia y González (2013) que la emplean en sus análisis de mensajes visuales. En este caso, registraremos las características formales -junto con otras variables de contenido como la temática o el género periodístico- de los mensajes de varias publicaciones para determinar las pautas de un sector, pero también para elaborar una propuesta de funcionalidad genérica del elemento estudiado: los grafismos. Se va a trabajar con lo que Igartua denomina variables manifiestas, es decir, las que "se refieren a los elementos que están físicamente presentes en los mensajes y que por ello pueden identificarse y cuantificarse con facilidad" (Igartua, 2006: 184).

La unidad mínima de análisis será una página, que es el elemento básico y numerado de este tipo de productos. Por regla general, analizaremos unidades que, en una única página, recopilen diversas noticias cuyo único nexo de unión será su temática (como cine, música o belleza) o incluso, en las secciones que recogen la información de actualidad, el único nexo común podrá ser la proximidad de las fechas en que acontecieron. A pesar de esto, la unidad visual mínima de la revista queda constituida por la página de modo que, en estos casos, se analizará la página de manera unitaria, por diverso que sea el contenido de la misma. En contraposición, existen secciones en las que el contenido informativo se extiende más allá de una página. Un claro ejemplo lo constituyen los reportajes o las entrevistas. En esta circunstancia, se considerará como unidad de análisis el número de páginas que abarque el contenido informativo.

\subsection{Hipótesis}

Las publicaciones impresas analizadas, de periodicidad mensual y que tienen como seña de identidad un cuidado tratamiento formal, deben ser un entorno idóneo para mostrar las variantes comunicativas de los recursos tipográficos. Así pues, los supuestos de partida de este trabajo de investigación se pueden agrupar en los siguientes enunciados que configuran las hipótesis:

- Los recursos gráficos son un elemento compositivo referencial para la elaboración de los mensajes periodísticos. Su presencia será abundante y variada. 
- Segunda. Los grafismos se caracterizan por su versatilidad funcional. Una misma tipología será empleada con diversas funciones, lo que debe asociarse a su frecuencia de uso.

Como otra aportación, ya enunciada, que consideramos oportuno reiterar aquí, pues será fruto del trabajo de campo, será la elaboración de una propuesta sistematizadora de las funcionalidades de los grafismos.

\section{Desarrollo de la investigación}

Tras concretarse el ámbito y periodo de estudio se decidió limitar el análisis a las páginas informativas. Seguidamente se procedió al registro de las unidades de análisis informativas del año tomado como referencia (2004) dio como resultado un global de 508 unidades, lo que suponía una media inferior a 43 unidades de análisis -exactamente la media era de 42,3- en cada ejemplar. Se definió una muestra de 96 unidades anuales y, con independencia de las unidades de análisis que tuviera cada ejemplar, se decidió analizar un número fijo, en concreto 8, para garantizar que todas las cabeceras tuviesen la misma representatividad.

Una vez definido que el análisis de 96 unidades -ocho en cada ejemplar- constituían una muestra representativa de un universo variable definido en torno a las 2032 unidades de análisis anuales $(508$ x 4 revistas $=2032)$, había que delimitar los ejemplares que se analizarían en el periodo de estudio de cinco años comprendido entre 2005 y 2009. Puesto que era pertinente analizar todas las cabeceras, al menos una vez, en cada uno de los meses del año, se creó una secuencia, ordenada alfabéticamente, según el nombre de la publicación, que se repitió sucesivamente, de modo que en el último año del ciclo (2009) se daba la misma secuencia que en el año inicial (2005). La figura 1 recoge las unidades de análisis (UA) de cada ejemplar consultado, en total 2800 UA, lo que supone un universo estimado de 11200 UA, realizándose una muestra total de $480 \mathrm{UA}$.

\begin{tabular}{|l|l|l|l|l|l|}
\hline & \multicolumn{1}{|c|}{2005} & \multicolumn{1}{|c|}{2006} & \multicolumn{1}{c|}{2007} & \multicolumn{1}{c|}{2008} & \multicolumn{1}{c|}{2009} \\
\hline Enero & Elle & Marie Claire & Telva & Vogue & Elle \\
\hline Febrero & Marie Claire & Telva & Vogue & Elle & Marie Claire \\
\hline Marzo & Telva & Vogue & Elle & Marie Claire & Telva \\
\hline Abril & Vogue & Elle & Marie Claire & Telva & Vogue \\
\hline Mayo & Elle & Marie Claire & Telva & Vogue & Elle \\
\hline Junio & Marie Claire & Telva & Vogue & Elle & Marie Claire \\
\hline Julio & Telva & Vogue & Elle & Marie Claire & Telva \\
\hline Agosto & Vogue & Elle & Marie Claire & Telva & Vogue \\
\hline Septiembre & Elle & Marie Claire & Telva & Vogue & Elle \\
\hline Octubre & Marie Claire & Telva & Vogue & Elle & Marie Claire \\
\hline Noviembre & Telva & Vogue & Elle & Marie Claire & Telva \\
\hline Diciembre & Vogue & Elle & Marie Claire & Telva & Vogue \\
\hline
\end{tabular}

Figura 1. Tabla con los ejemplares de las revistas que han sido objeto de análisis. Cabeceras: Elle, Marie Claire, Telva y Vogue (ediciones españolas). Elaboración propia. 
Seguidamente debía definirse qué unidades de análisis se estudiarían en cada ejemplar. Había que procurar que cualquier artículo pudiera ser objeto de estudio sin crear redundancias indeseadas. Para ello había que definir dos pautas: cuál sería la primera unidad de análisis estudiada en cada ejemplar y el intervalo para determinar las siguientes unidades de análisis. Así pues, para resolver estas cuestiones se crearon dos tablas, una que nos permitiría alternar la primera unidad objeto de análisis, con el fin de evitar que ésta no fuese siempre el sumario de la publicación o el editorial.

\begin{tabular}{lccccc}
\hline & 2005 & 2006 & 2007 & 2008 & 2009 \\
\hline Enero, febrero, marzo y abril. & 4 & 3 & 2 & 1 & 4 \\
Mayo, junio, julio y agosto. & 6 & 5 & 4 & 3 & 6 \\
Septiembre, octubre, noviembre y diciembre & 8 & 7 & 6 & 5 & 8 \\
\hline
\end{tabular}

Figura 2. Tabla que define la primera unidad que será objeto de estudio. Agrupamos los meses en bloques de cuatro, para que representen a cada una de las cuatro cabeceras. Elaboración propia.

A continuación se elaboró otra tabla que definía el intervalo a seguir, desde la primera unidad de análisis, para elegir las siete restantes. En la medida en que el ejemplar tuviese más unidades de análisis globales, el intervalo tendría que ser mayor para que así pudiera ser objeto de estudio cualquier unidad de análisis, con independencia de su ubicación en la publicación: al principio, en la parte intermedia o al final de la misma. De este modo se ha logrado que todo tipo de contenido periodístico -ya fuesen noticias, entrevistas, reportajes o artículos de opinión- haya sido objeto de análisis.

Por otra parte, se delimitaron las diferentes categorías que constituyeron la tipología de los recursos tipográficos usada como referencia:

- Filete: aquella línea cuyas principales características definitorias serían su grosor -medido en puntos- y dibujo, que puede manifestarse mediante más de una línea o incluso representarse a través de trazos discontinuos o puntos. Consideraremos filete cualquier tipo de línea, con independencia de su orientación, es decir, sea horizontal, vertical o diagonal.

- Subrayado: se trata de trazos (regulares o irregulares) que pretenden destacar una determinada porción textual. Si bien la propia etimología del término ofrece una exposición clara de su utilidad y forma de representación primigenia (sub, bajo o debajo de; -rayar, hacer o tirar rayas ${ }^{3}$ ) sus manifestaciones gráficas muestran una mayor variedad en la actualidad.

- Orla: es la repetición continuada de un motivo o viñeta -Martínez de Sousa define las viñetas como "dibujos o estampas que se utilizan como adorno" (Martínez de Sousa, 2005: 168)- con el fin de configurar un dibujo lineal.

- Recuadros: se entiende por tal un marco conformado mediante filetes u orlas.

${ }^{3}$ Definiciones extraídas de la edición en línea del diccionario de la R.A.E. Disponible en http://www.rae.es [Consultado por última vez el 22 de mayo de 2013]. 
- Topos o bolos: según la definición de González Díez y Pérez Cuadrado se entiende por topos o bolos aquellos "símbolos, signos o iconos [que] pueden ser regulares, -esto es, círculos, semicírculos, cuadrados, triángulos...- o figurativos, es decir, adoptando formas de figuras" (González Díez y Pérez Cuadrado, 2001: 119).

- Señalizadores: serían aquellos signos gráficos (como las flechas) que permiten asociar elementos en apariencia inconexos.

- Tramas y fondos: cuando la composición muestra alguna zona impresa -que comúnmente contendrá texto y/o imágenes- con una tonalidad distinta de la del papel, nos encontramos ante la inserción de una trama o fondo.

- Otros caracteres tipográficos: entendemos por tal aquellos caracteres representados fuera del texto periodístico lineal que han sido representados con una jerarquía inusual -en concreto, cuando se ha optado por aumentar exageradamente su tamaño- debido a las posibilidades comunicativas que este tipo de efectos permite. Nos referimos a los caracteres numéricos, las comillas, los paréntesis y corchetes o los signos de exclamación, entre otros, cuando se emplean con otros fines añadidos a los que les otorga el lenguaje.

Finalmente se definieron las variables registradas en el trabajo de campo que han sido: la presencia de grafismos en la unidad de análisis, la tipología del grafismo, el color $^{4}$ (característica presente en cualquier tipología) y, finalmente, la funcionalidad con la que se ha empleado.

\section{Resultados}

A continuación se exponen los resultados más significativos obtenidos en el trabajo de campo. La base de datos que se ha empleado en este artículo fue elaborada para la realización de la tesis doctoral del autor (Montes, 2013).

El primer dato significativo hace referencia al empleo de este recurso. Se confirma la relevancia de este componente del sistema gráfico, tanto cuantitativa como cualitativamente. En primer lugar, los grafismos están presentes en el $92,70 \%$ de los casos (445 sobre 480 unidades de análisis), lo que evidencia que los diseñadores se apoyan de manera recurrente en este elemento para elaborar los mensajes periodísticos. Queda patente la importancia de este recurso gráfico y justifica nuestro interés por su estudio. De cada diez artículos, en nueve se encuentra el lector algún tipo de grafismo y veremos que lo habitual es que el diseñador emplee varios en un mismo artículo. Cuando se trata de unidades de análisis de más de una página, el porcentaje asciende al 95,23\% (200 sobre 210 UA cuya extensión es superior a una página).

4 Estudios como el de Olmo (2005) ratifican que el correcto uso del color facilita la lectura del mensaje. 


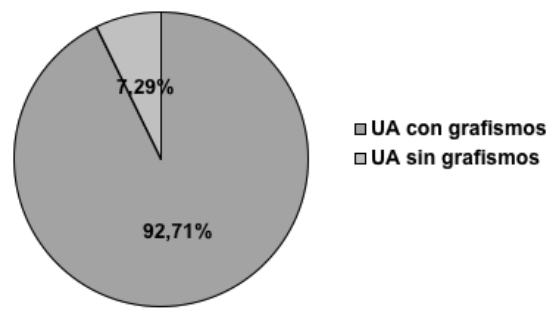

Figura 3: Presencia de grafismos. Elaboración propia.

El segundo dato a destacar es el de la diversidad funcional. De las 445 UA con grafismos, en $350 \mathrm{UA}^{5}(78,65 \%)$ aparece más de un grafismo. Es decir, un lector de las revistas femeninas -perciba o no su presencia- contempla habitualmente diversos grafismos en la mayoría de los artículos que consume y esto se debe a que el diseñador considera que su empleo favorece la decodificación del mensaje.

La inserción de los grafismos no está condicionada por ninguna temática o género periodístico. El $92,71 \%$ de presencia global se mantiene en porcentajes similares en las temáticas con mayor presencia como son: moda (de 111UA con esa temática, 95 tienen grafismos; 85\%), protagonistas (100 de 102UA; 98\%) u ocio (91 de 93UA; $97,84 \%)$. Un hecho similar sucede en los géneros periodísticos de referencia: noticias (de 178UA, 174 tienen grafismos; 97,75\%), reportajes (96 de 105UA; $91,42 \%$ ) y entrevistas (84 de 86UA; 97,67\%).

Entre los grafismos destacan cuatro categorías que son las más empleadas: trama/fondo (267 sobre $445 \mathrm{UA}$, $58,86 \%$ ), topo/bolo (220 UA, 49,43\%), subrayado (217 UA, $48,76 \%$ ) y recuadro (215 UA, 48,31\%). Se podría decir que cualquiera de estas cuatro tipologías son recursos gráficos básicos para el comunicador visual de las revistas objeto de estudio pues la tendencia que nos indican los datos sería la de su presencia en uno de cada dos diseños.

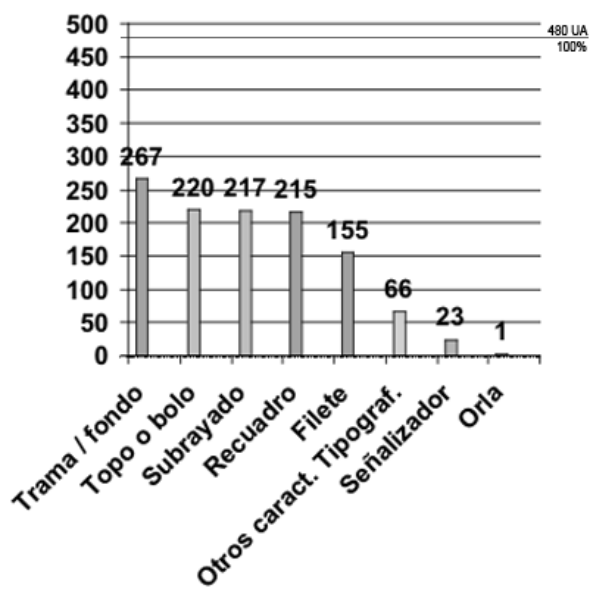

Figura 4. Tipología de los grafismos. Elaboración propia

En tercer lugar, nuestro interés se centra en la distribución de las diferentes funcionalidades de los grafismos y los datos nos confirman la versatilidad de este elemento. Se pretendía averiguar qué usos dan los diseñadores a los distintos grafismos,

${ }^{5}$ La combinación de dos (125 UA, 28,08\%) y tres (123 UA, 27,64\%) grafismos se da en porcentajes similares, mientras que las combinaciones de cuatro (72 UA, 16,17\%) o más de cuatro grafismos ( $30 \mathrm{UA}, 6,74 \%$ ) es menos frecuente. 
una vez comprobado que es un recurso muy empleado. En el primer modelo de análisis se tomó como punto de partida la clasificación de Costa (1992: 131-132), si bien la ficha final incluyó nuevas categorías, a tenor de los resultados obtenidos en el primer año testado. Por otro lado, puesto que ciertos autores consultados, como Gordon y Dodd (1994: 76), atribuyen connotaciones expresivas a algunos grafismos, se ha incluido en nuestra categorización inicial la funcionalidad connotativa. Así pues, en atención a la tarea que desempeñan en el mensaje visual, los grafismos se englobaron en cuatro categorías principales: estructurar, enfatizar, esclarecer y connotar.

Respecto al uso de las distintas funciones, las que aparecen con más frecuencia son la enfatizadora y la esclarecedora, que no son patrimonio de un grafismo concreto. Grafismos como los fondos o los recuadros se configuran como los más versátiles pues obtienen porcentajes parejos en distintas funcionalidades, lo que también explica su uso reiterado por los diseñadores.

Mención especial requieren las tramas o fondos. Estos recursos gráficos se han empleado en 267 UA. En su función enfatizadora aparecen en 148 ocasiones $(55,43 \%)$, de las cuales $130(48,68 \%)$ son representativas de la variable resalte. En su función esclarecedora se emplean en 132 ocasiones (49,43\%), de las cuales 117 $(43,82 \%)$ sirven para mejorar la legibilidad del binomio figura-fondo y en 89 casos $(33,33 \%)$ facilita la asociación de elementos del mensaje. Por último, en su función estructurante en el mensaje se usan en 87 ocasiones $(32,58 \%)$, ya sea para dividir partes de una misma información (68 UA), para separar informaciones distintas (59 UA) o diferenciar los contenidos informativos de las columnas de opinión (6 UA). Como se puede apreciar por los resultados, nos encontramos ante unos de los grafismos más versátiles -puesto que tiene una representación significativa en tres categorías funcionales y, a su vez, en subapartados muy diversos- de modo que no es de extrañar que sea el grafismo más empleado por los diseñadores.

En el extremo opuesto están otros grafismos que parecen servir sólo para ciertas funciones como sucede en el caso de los subrayados -empleado en el $99 \%$ de los casos para enfatizar- o en el de los bolos -usado para esclarecer el mensaje en un 97\%-. La principal aplicación de este último recurso, en las revistas de femeninas, no es el de marcar el inicio de los diferentes enunciados de un listado, sino que es muy empleado para indicar si un artículo continúa (para lo que se suele emplear la figura de un triángulo) o si, por el contrario, ha llegado a su fin (en este caso la figura usada es la de un cuadrado).

\subsection{Propuesta de funcionalidades de los grafismos}

El estudio de los recursos tipográficos permite definir unas categorías funcionales de este elemento -con independencia de los porcentajes de presencia en el ámbito de estudio-. Se trata de una propuesta del investigador que constituye un intento de sistematización de las funcionalidades de los grafismos. Tras registrar los diferentes usos de este elemento y asociarlos en categorías genéricas, consideramos que los grafismos realizan cuatro funciones principales: estructurar, enfatizar, esclarecer y connotar. 


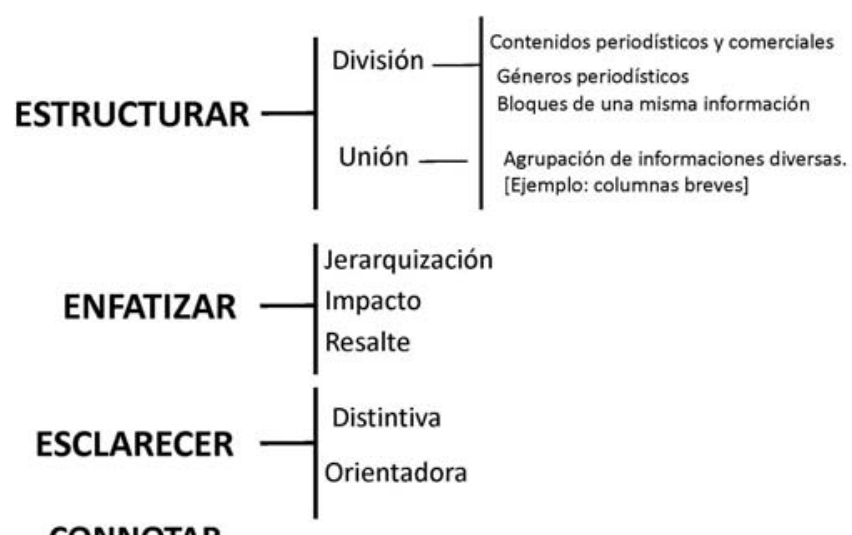

CONNOTAR

Figura 5. Propuesta de funcionalidades de los grafismos. Elaboración propia

Algunas de estas categorías se han dividido en subapartados (véase la figura 5) en la medida en que la diversidad de los casos hallados requería una mayor especificidad en la terminología, lo que no impedía que compartiesen una funcionalidad primigenia común. A continuación se explican las diferentes categorías de esta clasificación, con el fin de delimitar cada una de las distintas funcionalidades enunciadas.

Función estructurante. Los grafismos estructurantes del mensaje serían aquellos que dan forma a la estrategia de comunicación visual que previamente ha planificado el diseñador. En este apartado nos encontramos ante grafismos que contribuyen a la organización de las diferentes informaciones del mensaje por ejemplo, dividiendo los espacios y asociando los contenidos. Dentro de este grupo se incluyen los recuadros (con independencia de su forma: cuadrada, rectangular, circular, de contorno irregular, etc.), los filetes tipográficos (líneas de distinto grosor y orientación) y las tramas $\mathrm{y}$ fondos.

Dentro de la función estructurante distinguimos dos subapartados: división y unión.

- División: trata de crear áreas independientes entre sí. Puesto que en un producto editorial pueden confluir distintos tipos de mensajes, en una misma unidad compositiva, el diseñador debería establecer un patrón de diferenciación que permita al destinatario del mensaje discernir:

- Entre los contenidos periodísticos y los comerciales. Especialmente cuando la tecnología actual, en conjunción con la creatividad de los anunciantes, permite la constante innovación en el modo en que se presentan las inserciones publicitaria.

- Entre los distintos géneros periodísticos. Es decir, que el lector pueda distinguir entre los mensajes informativos (como son las noticias), los interpretativos (por ejemplo, las entrevistas o las crónicas) y los de opinión (como serían los artículos editoriales o los ensayos).

- Entre los distintos bloques de una misma información. Existe la posibilidad que en una única noticia confluyan contenidos diversos como son datos de actualidad junto con otros recopilatorios (como los datos cronológicos de 
un suceso que se ha extendido en el tiempo) o textos redactados por el periodista con declaraciones de alguno de los protagonistas de la información. En este tipo de casos, conviene elaborar propuestas formales diferenciadas para estos contenidos.

- Unión: este tipo de función persigue la creación de unidades compositivas que son producto de la suma e integración de unidades más reducidas. Esto no impide que conserven su propia identidad, si bien a efectos formales serían considerados como miembros de una unidad mayor. Un claro ejemplo sería la tradicional columna de breves.

Función enfatizadora. Los grafismos enfatizadores son aquellos cuya principal misión es la de otorgar relevancia a una zona de la composición, con el fin de adjudicarle mayor preponderancia frente a otras áreas, pudiendo incluso convertir una zona del diseño en el espacio de referencia de la composición. Conviene recordar que los grafismos son recursos que colaboran con los otros integrantes del sistema gráfico de modo que, por sí solos, es complejo que modifiquen sustancialmente el estatus de una determinada zona y la conviertan en un espacio de referencia en la composición. Naturalmente, cuanto más monótona sea la propuesta comunicativa cualquier elemento de mínimo contraste se convertirá en una zona de interés visual.

Así pues, la tarea enfatizadora de los grafismos no pretende abarcar únicamente funciones de jerarquización compositiva -como sería establecer diferentes grados de relevancia entre zonas- sino que también se incluyen bajo este epígrafe otras tareas como condicionar el itinerario de lectura o destacar elementos textuales o icónicos. Por tanto, la función enfatizadora de los recursos tipográficos se divide en tres tareas más específicas claramente diferenciadas: jerarquización, impacto y resalte.

- Jerarquización: esta función acontece cuando los grafismos refuerzan la relevancia de una determinada zona compositiva. Se pueden emplear en este apartado grafismos tales como los filetes, los recuadros, las tramas y fondos. En este caso, el papel del grafismo será, normalmente, secundario ya que otras variantes como la ubicación de los elementos o la superficie compositiva que cubren serán determinantes.

- Impacto: esta función contribuye a la creación de puntos de interés visual en la composición que permiten al diseñador configurar cuidadosamente el itinerario de lectura más acorde al contenido del mensaje. Serán específicos de este tipo de función grafismos tales como los recuadros, además de las tramas y fondos. La subdivisión de grafismos denominada otros caracteres tipográficos e incluso subrayados de grandes dimensiones también podrían desempeñar, entre otras funciones, la de impacto. Los recursos tipográficos tampoco serán un elemento de primer orden en esta ocasión -salvo en una composición cuyos mensajes no contengan imágenes-, pues el elemento icónico será siempre el principal recurso para la creación de puntos de interés visual. Tal y como demostraron los estudios de García y Stark (1991: 70) las áreas con fotografías son las que primero atraen la vista de los lectores. En la medida en que se inserten 
en una composición carente o escasa de otros elementos que capten la atención, los grafismos se podrían configurar como el centro de interés visual del diseño.

- Resalte: esta función se cumple en aquellos casos en los que los grafismos realzan ciertos epígrafes textuales o icónicos, aunque la relevancia de estos destacados en el global de la composición es mínimo. Serán específicos de este tipo de función los subrayados (en el caso de los textos) y los recuadros (por lo que se refiere a las imágenes). No obstante, grafismos tales como los pertenecientes al apartado otros caracteres tipográficos, las orlas, los topos o bolos e incluso las tramas y fondos podrían desempeñar esta tarea. En este caso, el objetivo es más modesto ya que no es preciso configurarse como el centro de interés visual y, por tanto, es más factible que un grafismo, por sí solo, logre este resalte.

Función esclarecedora. Entendemos por grafismos esclarecedores todos aquellos que contribuyen a presentar un mensaje formal más claro y comprensible que facilite al destinatario del mismo su tarea de decodificación. Cuando el grafismo incide en la mejora del aspecto de los contenidos lingüísticos se considera que es una función de refuerzo mientras que si persigue el correcto entendimiento del mensaje global -si su presentación es confusa o inadecuada- se trataría de una función esclarecedora. Distinguimos dentro de esta categoría dos apartados: distintiva y orientadora.

- Distintiva. Cuando el diseñador considera que la presentación de los diferentes integrantes del mensaje lingüístico no es lo suficientemente explícita de la intencionalidad del productor del mensaje, puede recurrir a los grafismos a fin de mejorar su aspecto formal mediante la distinción. Los grafismos propios de esta función aclaratoria serán similares a los que realizaban la tarea de resalte ya que cualquier variación formal aplicada a un contenido textual supondrá otorgarle una cierta distinción. Así pues, los subrayados y los grafismos correspondientes al apartado otros caracteres tipográficos serían dos de las categorías que se encuadran en esta tarea de refuerzo en la que merecen una atención especial los topos o bolos. Estos grafismos son un ejemplo específico de esta función cuando su presencia nos permite distinguir entre los distintos epígrafes de un listado o enumeración. En estos casos no se pretende resaltar ese contenido sobre otro e incluso entre los diferentes enunciados se busca transmitir la sensación de uniformidad. También merecen consideración especial los filetes y las tramas o fondos ya que se convierten en sencillos recursos que, sin embargo, demuestran ser de gran eficacia y utilidad cuando tenemos que trabajar con una información compleja como puede ser cualquier tabla, en especial si ésta contiene gran cantidad de datos que demanden la inserción de numerosas filas y columnas. El uso de filetes y tramas o fondos nos permitirá distinguir claramente la información correspondiente a cada columna o fila facilitando y abreviando el tiempo de la consulta.

- Orientadora. Aclarar cualquier duda que pudiese tener el destinatario del mensaje es la tarea de los grafismos cuya funcionalidad hemos denominado orientadora. Por norma general, estas dudas serán producto de una distribución compositiva difícil de decodificar ya sea debido la complejidad del contenido 
o a una disposición ambivalente o directamente incorrecta de los elementos. Los grafismos que tienen esta función específica son los que hemos denominado señalizadores. En el ámbito de estudio que nos atañe, las revistas de femeninas, los grafismos con función orientadora de uso frecuente son aquellos con apariencia de flechas trazadas a mano alzada. En numerosas ocasiones, debido a la cantidad de material gráfico presente en determinadas páginas, al maquetador le resulta una tarea compleja colocar el texto alusivo a cada fotografía al lado de ésta. Además, aunque el diseñador consiga resolver este problema es posible que el texto esté igualmente próximo a otras imágenes y no resulte fácil asociar ambas informaciones (icónica y textual).

Función connotativa. Entendemos por grafismos connotativos aquellos que conllevan un significado implícito en su representación ya sea por su dirección, orientación, forma o color. Para ejemplificar esta función diremos que, en un reportaje con fotografías de jóvenes deportistas, la inclusión de un simple marco puede aportar numerosas connotaciones según su representación (por ejemplo, un tono naranja saturado transmite dinamismo lo que se puede reforzar con un contorno irregular y una orientación diagonal). En este apartado se incluirían también las connotaciones que autores como Gordon y Dodd (1994: 76) atribuyen a las distintas representaciones de la categoría denominada otros caracteres tipográficos como serían que las comillas evocan comunicación personal o que los interrogantes demandan una contestación.

\section{Conclusiones}

A tenor del análisis de los resultados obtenidos durante el trabajo de campo, se obtienen las siguientes conclusiones:

Primera. Se confirma la relevancia de este componente del sistema gráfico. Comprobamos, además, que el alto porcentaje de uso de los grafismos no se fundamenta en el empleo reiterado de una tipología, puesto que la tendencia dominante es la inserción de más de un grafismo en la unidad de análisis, quizás con el fin de sacar partido a su diversidad funcional. Cuando en una publicación, con independencia del soporte, se representan mensajes periodísticos, la ausencia de los recursos tipográficos no textuales se convierte en un hecho excepcional. Está presente en todo tipo de artículos con independencia de su extensión, temática o género periodístico.

Segunda. No podemos afirmar que la versatilidad funcional sea una característica unánime, adjudicable a todos los grafismos. Si bien las tramas o fondos, los recuadros o los filetes son recursos que pueden emplearse para distintas funciones compositivas, otros elementos como los subrayados o los topos o bolos tienen un uso recurrente, los primeros para enfatizar y los segundos para esclarecer. Así pues, el uso combinado de las distintas tipologías, apoyado en la diversidad funcional de algunas categorías, parece sustentar el elevado uso que los diseñadores hacen de los grafismos.

Si bien el estudio de esta investigación se ha limitado a un tipo de publicaciones, de un ámbito y en un periodo concreto, entendemos que la variedad de los mensajes periodísticos analizados nos permiten, no sólo extraer conclusiones concretas del sector analizado, sino elaborar una propuesta válida de sistematización de las funciona- 
lidades de los grafismos. Como es lógico, dicha clasificación deberá actualizarse, con el tiempo, para dar cabida a nuevos recursos formales o funciones que pudiesen surgir y en la medida en que no tuviesen acomodo en las categorías ahora definidas.

\section{Referencias bibliográficas}

CABELLO, Fernando (1999): El mercado de revistas en España. Concentración informativa. Barcelona, Ariel.

CANGA, Jesús (1994): El diseño periodístico en prensa diaria. Barcelona, Bosch.

COSTA, Joan (1992): "Los recursos combinatorios del grafismo funcional", en MOLES, Abraham y JANISZEWSKI, Luc (comps.): Grafismo funcional. Barcelona, Ediciones CEAC, págs. 121-151.

GARCÍA, Mario \& STARK, Pegie (1991): Eyes on the news. Florida, The Poynter Institute.

GARCÍA YRUELA, Jesús (2003): Tecnología de la comunicación e información escrita. Madrid, Síntesis.

GONZÁLEZ DÍEZ, Laura y PÉREZ CUADRADO, Pedro (2001): Principios básicos sobre diseño periodístico. Madrid, Editorial Universitas.

GONZÁLEZ DÍEZ, Laura y PÉREZ CUADRADO, Pedro (2014): "La cabecera como signo de identidad del producto periódico: una aproximación teórico-práctica a los rótulos de la prensa diaria española en 2013", en Icono 14, volumen 12, págs. 3162: http://www.icono14.net/ojs/index.php/icono14/article/view/637/447 [Consulta: 11 de febrero de 2014]

GORDON, Maggie y DODD, Eugenie (1994): Tipografia decorativa. Barcelona, Gustavo Gili.

HEREDIA ECHEVARRI, María Angélica y GONZÁLEZ DÍEZ, Laura (2013): “La carencia de contexto escrito en la fotografía periodística: una aproximación a la utilización del pie de foto en la prensa diaria chilena". Index.comunicación, $\mathrm{n}^{\mathrm{o}} 3$, págs.: 87-120. http://journals.sfu.ca/indexcomunicacion/index.php/indexcomunicacion/article/view/60 [Consulta: 11 de febrero de 2014].

IGARTUA, Juan José (2006): Métodos cuantitativos de investigación en comunicación. Barcelona, Bosch.

JOLY, Martine (1999): Introducción al análisis de la imagen. Buenos Aires, La Marca.

MARTíN AGUADO, José Antonio y ARMENTIA VIZUETE, José Ignacio (1995): Tecnología de la Información Escrita. Madrid, Síntesis.

MARTÍNEZ DE SOUSA, José (2005): Manual de edición y autoedición. Madrid, Pirámide.

MENÉNDEZ MENÉNDEZ, María Isabel (2013): “Tipología de la prensa femenina. Una propuesta de clasificación". Estudios sobre el mensaje periodístico, vol. 19, n ${ }^{\circ}$ 1, págs. 191-206. Madrid, Servicio de Publicaciones de la Universidad Complutense. 
MONTES, Manuel (2013): Análisis del diseño gráfico de las revistas de moda en España, desde una perspectiva cromática. Fuenlabrada, Universidad Rey Juan Carlos.

OLMO, Jesús del (2004): Implantación, análisis y perspectivas del color en la prensa diaria española. Madrid, Universidad Complutense de Madrid.

OLMO, Jesús del (2005): "El color como elemento funcional en el diseño del mensaje periodístico". Estudios sobre el mensaje periodístico, vol. 11, págs. 425-440. Madrid, Servicio de Publicaciones de la Universidad Complutense.

OWEN, William (1991): Diseño de revistas. Barcelona, Gustavo Gili.

ZORRILLA, Jesús (1999): Introducción al diseño periodístico. Navarra, Ediciones Universidad de Navarra. 